\title{
ANALISIS PENGARUH MODEL SAMBUNGAN TERHADAP KEKUATAN STRUKTUR AKIBAT GETARAN MESIN INDUK PADA KAPAL KAYU DENGAN METODE EXPERIMENTAL MODAL ANALYSIS DAN SIMULASI
}

\author{
Debby R. Lekatompessy \\ debby.lekatompessy@gmail.com \\ Jurusan Teknik Perkapalan, Fakultas Teknik Universitas Pattimura Ambon.
}

\begin{abstract}
ABSTRAK
Mesin induk pada kapal yang beroperasi menghasilkan getaran. Getaran yang dihasilkan diteruskan ke struktur pondasi mesin melalui kanal dan balok pondasi. Getaran sisa akan diteruskan ke struktur konstruksi di daerah kamar mesin. Distribusi beban dinamis pada konstruksi dipengaruhi oleh kondisi sambungan-sambungan yang ada. Agar getaran mesin induk dapat terdistribusi merata maka sambungan konstruksi di daerah kamar mesin harus kaku atau terikat dengan baik.

Penelitian ini bertujuan untuk mengatasi amplitude yang terjadi pada titik-titik sambungan dengan melakukan analisa terhadap karakteristik getaran pada model sambungan di daerah kamar mesin struktur kapal kayu. Penelitian ini juga ingin membuktikan bahwa resonansi lokal dapat diatasi dengan memperbaiki model sambungan dan melalui peningkatan nilai kekakuan sambungan. Penelitian ini fokus pada 4 model sambungan.

Penelitian awal difokuskan pada eksperimen model sambungan. Uji defleksi dilakukan untuk memperoleh nilai elastisitas dan kekakuan material. Kemudian dilakukan Uji eksitasi. Pemodelan sambungan dilakukan dengan bantuan simulasi. Kemampuan masing-masing model sambungan dalam mendistribusikan beban dinamis terlihat melalui nilai amplitude yang terjadi. Sedangkan pola defleksi dapat diperoleh dengan menganalisa mode shape masing-masing model sambungan.

Hasil penelitian menunjukkan bahwa model sambungan berpengaruh pada nilai amplitude yang terjadi pada sistem. Pada penggunaan alat sambung yang sama, masing-masing model menghasilkan amplitude yang berbeda.
\end{abstract}

Kata Kunci: Amplitude, Beban dinamis, Mode shape, Model sambungan, Resonansi.

\section{PENDAHULUAN}

Kerusakan parah pada struktur kapal sebagian besar disebabkan oleh deformasi dan konsentrasi tegangan dinamis yang tinggi dari getaran frekuensi rendah. Getaran lambung kapal secara umum dapat diklasifikasikan ke dalam dua kategori, yaitu getaran global dan lokal. Getaran lokal terjadi ketika adanya resonansi hanya pada bagian terisolasi dari struktur kapal. Resonansi lokal dapat diatasi secara lokal dengan memodifikasi komponen struktural beresonansi atau dengan menambahkan penyerap getaran dan perangkat redaman. Mesin utama dan mesin bantu dapat langsung menyebabkan getaran melalui beban dinamis yang disalurkan melalui dudukan dan pondasinya. Penentuan sumber getaran, adalah penting untuk menetapkan frekuensi eksitasi dan untuk menghubungkan frekuensi eksitasi dengan frekuensi rotasi poros, dengan menentukan jumlah osilasi per revolusi poros (Yucel dan Arpaci, 2013).

Faktor keselamatan, keandalan dan kontrol kualitas menjadi hal yang sangat penting untuk dipertimbangkan dan tidak dapat dihindari. Karena itu, perlu dilakukan pengembangan teknik analisis dan teknologi pengukuran karakterisasi material (Tan, et al. 2011).

Kayu tergolong dalam material orthotrop karena memiliki sifat yang unik. Sifat mekanik kayu menjadi perhatian khusus dari Dugdale (1984), melalui eksperimen dengan menggunakan modulus young dan poisson's ratio.

Penelitian berlanjut dimana Dickinson et al (1986) melakukan studi Flexural Vibration dan Buckling untuk material isotropic dan orthotrop menggunakan metode Rayleigh-Ritz. Studi eksperimen dari flexural vibration untuk material orthotrop dengan menggunakan teori viscoelastic, dimana nilai faktor damping Poisson's ratio merupakan nilai empiris (Nakao et al., 1987). Menggunakan pendekatan yang hampir sama David et al. (1999) melakukan penelitian menggunakan dua nilai elastisitas dan rigidity, eksperimen dilakukan pada 2 spesimen dengan ukuran tebal pelat kayu yang berbeda. Hasilnya menunjukkan bahwa elastisitas dari 
material kayu dapat didekati dengan menggunakan tiga nilai modulus elastisitas $E$, tiga nilai rigidity $G$ dan enam nilai poison's ratio $\mu$. Hasil uji dibandingkan dengan menggunakan Ritz method dan Rayleigh method. Ritz method digunakan untuk menghitung koefisien amplitude. Hal ini telah dilakukan oleh beberapa peneliti dengan pendekatan dan metode yang berbeda-beda. Seperti Bruce et al. (1997) yang merekomendasikan bahwa metode Load Resistance Factor Desain (LRFD) dalam perancangan konstruksi kayu dapat digunakan. Boss et al. (2003) menyatakan bahwa metode Rayleigh-Ritz sangat baik untuk mengestimasi frekuensi resonansi pada pelat orthotrop dimana hasil dapat dilihat pada mode shape $(i, j)$.

Schwarz dan Richardson (1999), Tan et al. (2011) menyatakan bahwa karakteristik suatu material dapat diketahui dengan menggunakan teknik vibrasi yaitu menggunakan metode Experimental Modal Analysis (EMA) dimana pengukuran $F R F$ dilakukan dengan menggunakan FFT analyzer, cara ini sudah dikenal sejak tahun 1970. Tan et al. (2011), Alfano dan Pagnotta (2006) membuktikan bahwa karakteristik material dapat diketahui melalui uji impact hammer yang menghasilkan performa dari resonansi getaran. Anuar et al. (2012) dalam penelitiannya menggunakan EMA untuk mengetahui karakteristik dinamis (modal parameter) dari Printed Circuit Board (PCB).

Penelitian ini menganalisa model sambungan terhadap karakteristik parameter getaran pada daerah konstruksi kamar mesin kapal kayu. Metode yang digunakan adalah metode EMA melalui uji eksitasi menggunakan impact hammer dimana pengukuran $F R F$ menggunakan FFT analyzer. Hasil penelitian berupa data base material dan model 3D simulasi yang bertujuan mendeteksi dini daerah kritis agar kerusakan struktur dapat dihindari dengan cara mengatur letak dan jenis sambungan.

\section{KAJIAN TEORI DAN METODE}

\section{Experimental Modal Analysis (EMA)}

Metode ini digunakan sejak tahun 1970 untuk mencari modus getar dari mesin dan struktur. Cara umum yang digunakan adalah dengan menentukan modal parameter dari struktur (Schwarz dan Richardson, 1999).

Fakultas Teknik Universitas Pattimura,
ISSN : 2620-3995

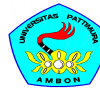

\section{Frequency Response Function (FRF)}

$F R F$ menggambarkan hubungan input-output seperti yang ditunjukkan pada Gambar.1 yang menunjukkan bahwa FRF didefinisikan sebagai rasio Transformasi Fourier dari respon output $(X$ $(\omega)$ ) dibagi oleh Fourier transform dari gaya input $(\mathrm{F}(\omega))$ yang menyebabkan output.

Sementara itu, Pengukuran FRF pada Struktur dalam Bentuk Matrix dapat dilihat pada gambar 2 .

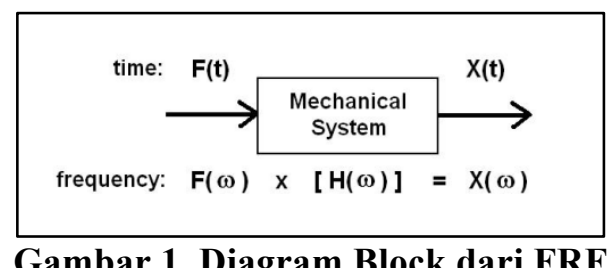

Cara yang populer saat ini adalah pengukuran $F R F$ melalui uji impact dengan menggunakan FFT analyzer. Hal ini ditunjukkan pada Gambar 3.

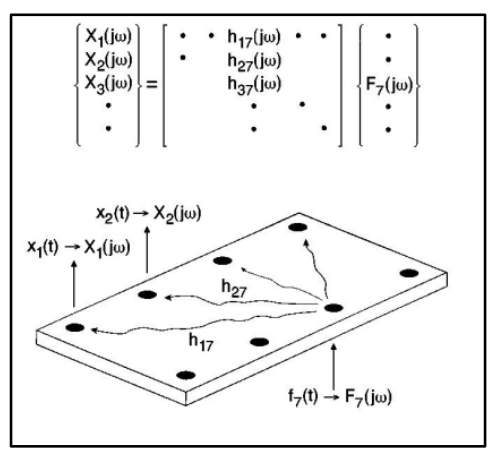

\section{Gambar 2. Pengukuran FRF pada Struktur dalam Bentuk Matrix}

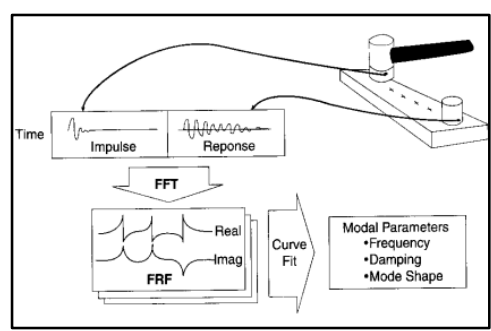

Gambar 3. Uji Impact

\section{Getaran Pada Material Orthotrop}

Pendekatan-pendekatan yang telah dilakukan yaitu melalui uji eksperimental dan simulasi seperti yang dilakukan oleh Dugdale (1984); Dickinson dan Di Blasio (1986); Nakao et al (1987); Lin et al (2009). Metode lainnya yang digunakan untuk menganalisis getaran yaitu 
secara numerik dilakukan oleh Bos dan Casagrande (2003), LRFD oleh Bruce (1997), dan SEA oleh Craik dan Galbrun (2005).

\section{Modal Parameter}

Ada 2 cara yang dapat digunakan untuk memperoleh modal parameter, yaitu: Finite Element Modelling (analitik) dan Experimental Modal Analysis (set FRF).

\section{Analisis Respons Dinamis Kapal}

Van Gunsteren (1974) menggunakan dua-simpul modus getaran vertikal dari dua model kapal dengan menggunakan teori strip yang telah dimodifikasi. Finite Element Analysis (FEA) digunakan dalam analisis dan desain struktur kapal yang lebih kompleks (Hughes, 1988). Sementara, Xia et al. (2000), menggunakan FEA untuk memprediksi respon global dari struktur kapal.

Penampang melintang konstruksi utama kapal kayu dapat dilihat pada Gambar 4.

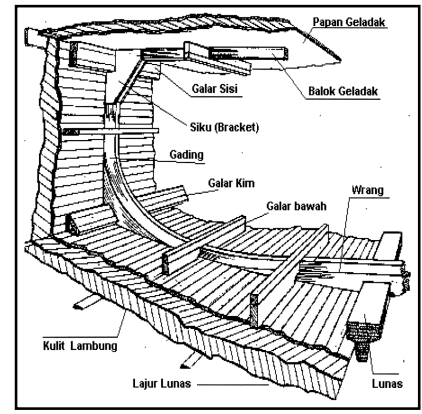

Gambar 4. Penampang Melintang Kapal Kayu dengan Beberapa Bagian Konstruksi Utama

\section{Metode}

\section{Uji Defleksi}

Uji defleksi dilakukan terhadap 5 sampel dengan arah serat radial dan 5 sampel dengan arah serat tangensial.

\section{Uji Eksitasi}

Uji eksitasi dilakukan terhadap model balok sederhana dengan model jepit cantilever beam.

Uji eksitasi dibagi dalam dua kelompok besar yaitu:

1. Uji eksitasi terhadap material tanpa sambungan dengan arah serat $R$ dan $T$ (2 potong).

2. Uji eksitasi terhadap kayu sambungan dengan variasi arah serat, alat sambung dan model sambungan (36 potong).

Fakultas Teknik Universitas Pattimura,

ISSN : 2620-3995

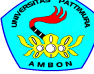

Terdapat empat jenis sambungan yang digunakan, yaitu takik miring (Model I), takik miring berkait (Model II), takik lurus (Model III) dan takik lurus berkait (Model IV). Alat sambung yang digunakan adalah baut, paku dan pasak.

Uji eksitasi menggunakan Hammer Test dengan setting alat seperti pada Gambar 5, untuk menghasilkan set Frequency Response Function $F R F$ dalam mencari nilai parameter getaran:
a. Compliance a $(\mathrm{m} / \mathrm{N})$
b. Kekakuan dinamis $k(N / m)$
c. Frekuensi Natural $\omega_{0}(\mathrm{~Hz})$
d. Rasio Redaman $\xi$
e. Rasio Transmisi $T R$

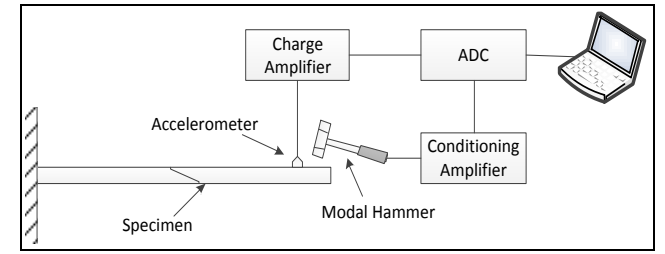

Gambar 5. Setting Alat Pengujian Eksitasi

\section{Experimental Modal Analysis}

Modal frekuensi adalah frekuensi puncak pada curve fitting, sedangkan Modal damping diperoleh dari lebar half power band with.

\section{Mode Shape Material}

Mode shape diperoleh dari data titik di modus 1 yaitu pada frekuensi terendah (ada 8 titik) / material.

\section{Karakteristik Getaran Berdasarkan Hasil Simulasi}

Hasil simulasi berupa tabel, grafik dan distribusi beban dinamis pada konstruksi kamar mesin kapal kayu. Data dimasukkan secara manual yang memperlihatkan distribusi beban dan daerah kritisnya.

\section{HASIL DAN PEMBAHASAN}

\section{Perhitungan Getaran Mesin}

Modal analisis digunakan untuk menemukan nilai frekuensi natural suatu sistem, di mana boundary condition tidak melibatkan gaya dari luar sistem. Pada penelitian ini modal analisis dilakukan dengan menggunakan kondisi batas fixed support pada bagian lunas dan ujung dari sebagian gading. Sistem dieksitasi pada frekuensi pribadinya. Besarnya frekuensi tergantung pada massa dan kekakuan sistem 
tersebut. Arah getaran yang terjadi dibatasi dalam arah horisontal dan vertikal

Tabel 1. Modal Analisis Sistem Tanpa Sambungan

\begin{tabular}{|c|c|}
\hline Mode ke-n & $\begin{array}{c}\text { Frekuensi } \\
\text { natural }(\mathrm{Hz})\end{array}$ \\
\hline 1 & 27,263 \\
\hline 2 & 34,798 \\
\hline 3 & 36,874 \\
\hline 4 & 45,454 \\
\hline 5 & 47,105 \\
\hline 6 & 54,412 \\
\hline
\end{tabular}

Grafik hubungan antara Frekuensi dengan Amplitude sistem tanpa sambungan dapat dilihat pada Gambar 6.

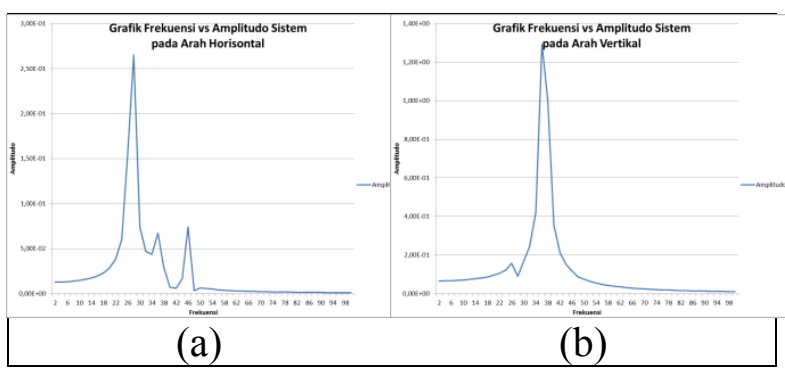

Gambar 6. Grafik Frekuensi vs Amplitude Struktur Tanpa Sambungan (a) Arah Horisontal dan (b) Arah Vertikal

Harmonic Response pada penelitian ini adalah getaran sistem yang timbul sebagai akibat kerja dari mesin induk yang dikancingkan di atas kanal dan struktur dibawahnya. Getaran berupa gaya yang dihasilkan akibat dari eksitasi torsi gas mesin dan beban mesin itu sendiri. Getaran didistribusikan ke seluruh bagian struktur yang saling terikat.

Grafik hubungan antara Frekuensi dengan Amplitude struktur yang menggunakan sambungan baut dapat dilihat pada Gambar 7 .

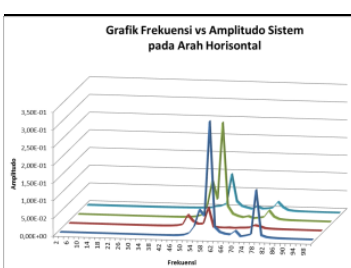

(a)

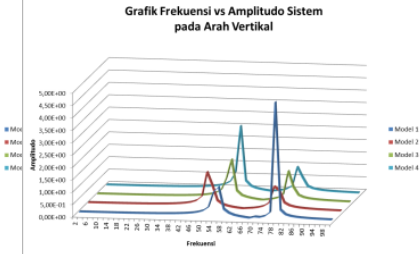

(b)

Gambar 7. Grafik Frekuensi vs Amplitude Struktur Menggunakan Alat Sambung Baut (a) Arah Horisontal dan (b) Arah Vertikal

Fakultas Teknik Universitas Pattimura,

Hasil simulasi berupa FRF dalam bentuk grafik dan tabel dari penelitian ini akan membantu untuk melihat alat sambung dan model sambungan yang terbaik dimana deformasi akibat transmisi gaya dari kerja mesin yang diperoleh sekecil mungkin akan direkomendasikan untuk digunakan.

Total deformasi untuk sambungan baut, dalam arah horisontal dan vertikal, dengan empat model sambungan dapat dilihat pada Gambar 8 sampai Gambar 11.

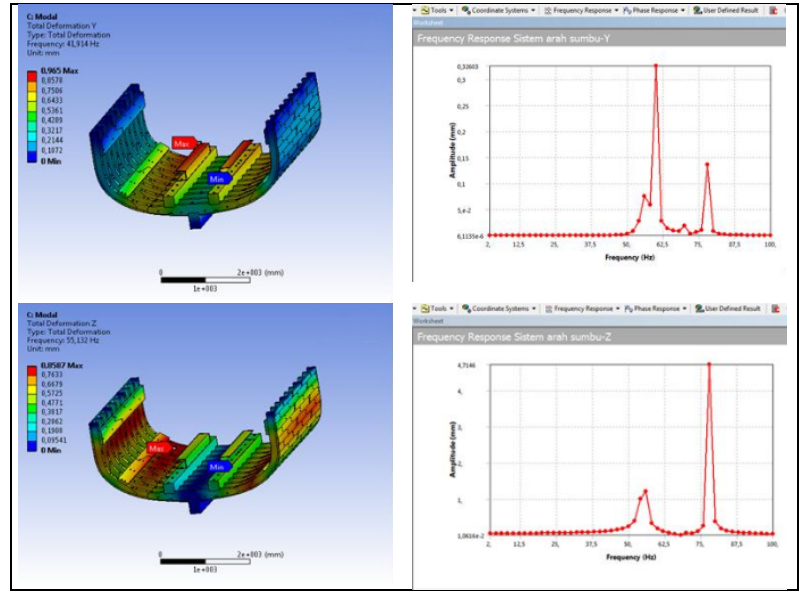

Gambar 8. Total Deformasi Sambungan Model I dengan Alat Sambung Baut pada Arah Horisontal dan Vertikal

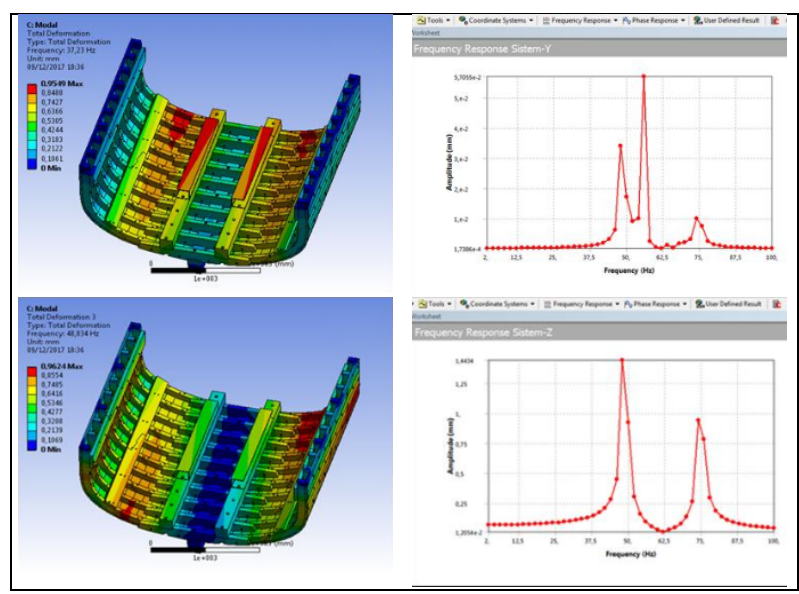

Gambar 9. Total Deformasi Sambungan Model II dengan Alat Sambung Baut pada Arah Horisontal dan Vertikal 


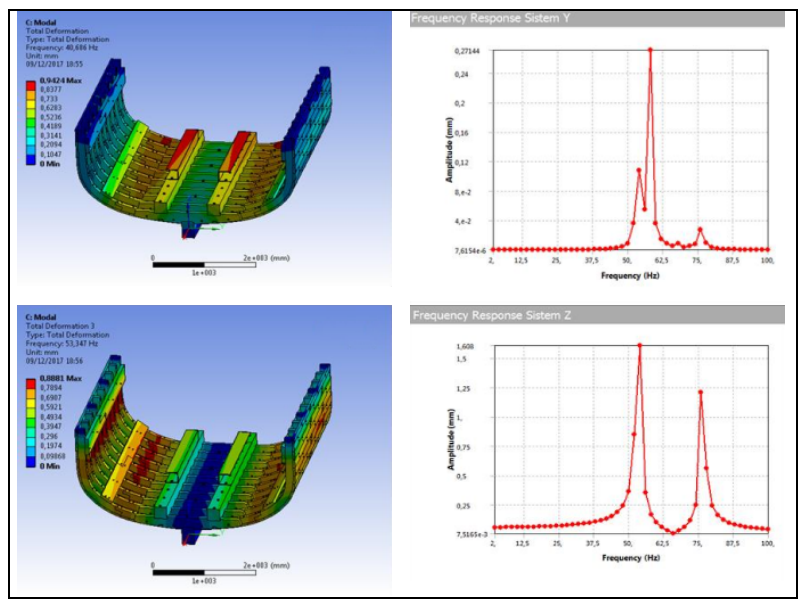

Gambar 10.Total Deformasi Sambungan Model III dengan Alat Sambung Baut pada Arah Horisontal dan Vertikal

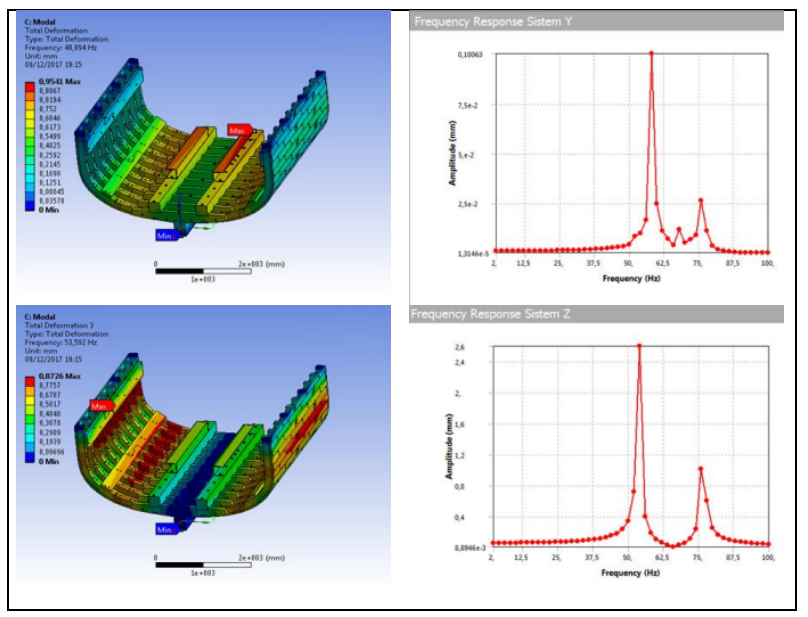

Gambar 11.Total Deformasi Sambungan Model IV dengan Alat Sambung Baut pada Arah Horisontal dan Vertikal

Grafik hubungan antara Frekuensi dengan Amplitude struktur yang menggunakan sambungan paku dapat dilihat pada Gambar 12.

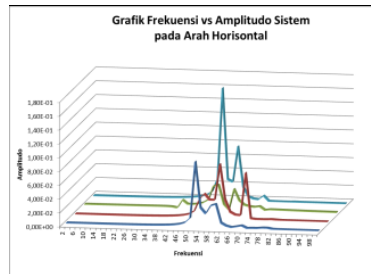

(a)

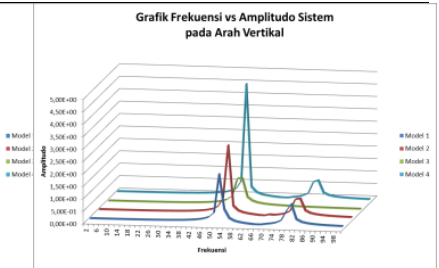

(b)
Gambar 12. Grafik Frekuensi vs Amplitude Struktur dengan Alat Sambung Paku (a) Arah Horisontal dan (b) Arah Vertikal
Grafik hubungan antara Frekuensi dengan Amplitude struktur yang menggunakan sambungan pasak dapat dilihat pada Gambar 13.

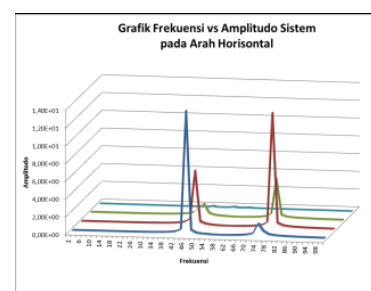

(a)

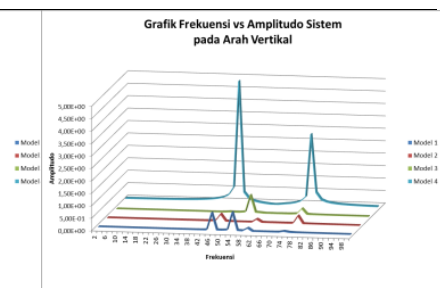

(b)
Gambar 13. Grafik Frekuensi vs Amplitude Struktur Menggunakan Alat Sambung Pasak (a) Arah Horisontal dan (b) Arah Vertikal

\section{Pengaruh Model Sambungan Terhadap Karakteristik Getaran}

Karakteristik getaran yang terjadi pada sistem pada masing-masing model dapat dilihat pada Gambar 14. Grafik menunjukkan adanya perubahan nilai amplitude pada masing-masing model. Amplitude yang tinggi mengindikasikan bahwa struktur kurang baik dalam pengikatan.

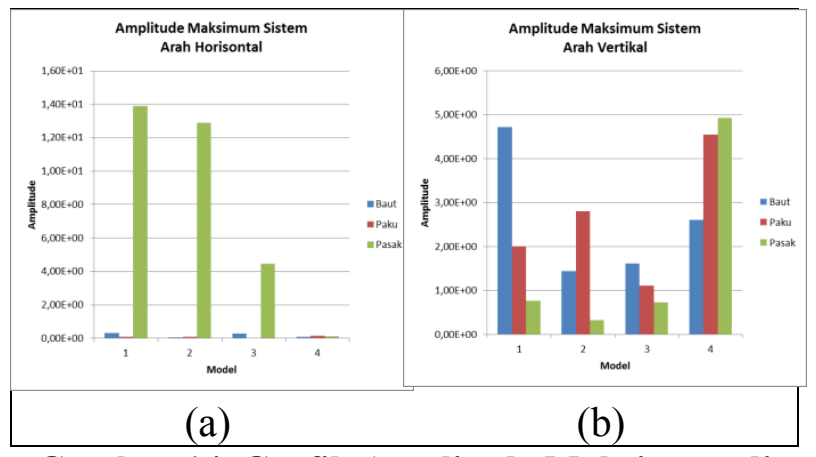

Gambar 14. Grafik Amplitude Maksimum di Frekuensi Eksitasi (a) Arah Horisontal dan (b) Arah Vertikal

\section{KESIMPULAN}

Berdasarkan hasil penelitian ini maka dapat disimpulkan beberapa hal sebagai berikut:

1. Model sambungan berpengaruh pada nilai amplitude yang terjadi pada sistem. Pada penggunaan alat sambung yang sama, masing-masing model menghasilkan amplitude yang berbeda.

2. Pada penggunaan alat sambung baut maka nilai amplitude dalam arah horisontal secara berturutan dari yang terkecil adalah model II $0,057 \mathrm{~mm}$, model IV $0,101 \mathrm{~mm}$, model III $0,271 \mathrm{~mm}$ dan model $\mathrm{I} 0,326 \mathrm{~mm}$. Alat 
sambung baut memiliki pengikatan terbaik pada model II. Alat sambung paku memiliki pengikatan terbaik pada model III dengan nilai amplitude $0,035 \mathrm{~mm}$ dan alat sambung pasak pada model IV dengan nilai amplitude $0,123 \mathrm{~mm}$.

3. Pada penggunaan alat sambung baut maka nilai amplitude dalam arah vertikal secara berturutan dari yang terkecil adalah model II $1,44 \mathrm{~mm}$, model III 1,61 mm, model IV 2,60 $\mathrm{mm}$ dan model I 4,71 mm. Jika yang dipilih adalah alat sambung baut maka model yang memiliki pengikatan terbaik adalah model II. Jika yang dipilih adalah alat sambung paku maka model yang memiliki pengikatan terbaik adalah model III dengan nilai amplitude $1,1 \mathrm{~mm}$ dan jika yang dipilih adalah alat sambung pasak maka model yang memiliki pengikatan terbaik adalah model II dengan nilai amplitude $0,326 \mathrm{~mm}$.

4. Nilai amplitude menunjukkan kekakuan dari sistem dimana semakin kecil nilai amplitude yang terjadi maka struktur semakin kaku.

\section{DAFTAR PUSTAKA}

Alfano, M. dan Pagnotta, L. 2006. Determining the elastic properties of isotropic materials by modal vibration testing of rectangular thin plates. Journal of Sound and Vibration (293). p426-39.

Anuar, M.A., Isa, A.A.M. dan Ummi Z.A.R. 2012. Modal characteristics study of CEM1 single-layer printed circuit board using experimental modal analysis. International Symposium on Robotics and Intelligent Sensors 2012 (IRIS 2012) Procedia Engineering (41). p1360-1366.

Schwarz, B.J dan Richardson, M.H. 1999. Experimetal Modal Analysis. Jamestown California 95327: Vibrant Technology, Inc.

Bos, F., dan Casagrande, S.B. 2003. On-line non-destructive evaluation and control of wood-based panels by vibration analysis. Journal of Sound and Vibration (268). p403-412.

Bruce R.E. 1997. Probability-Based LRFD for Engineered Wood Construction. Structural Safety (19). p53-65.

Kretschmann, D.E. 2008. The influence of juvenile wood content on shear parallel, compression, and tension perpendicular to grain strength and mode I fracture toughness of loblolly pine at various ring orientation. Forest Products Journal (58). p89-96.

Green, D.W., Winandy, J.E dan Kretschma, D.E. 1999. Mechanical Properties of Wood, Forest Wood handbook Products Laboratory.

Dickinson, S.M., Di Blasio, A. 1986. On the use of orthogonal polynomials in the rayleighritz method for the study of the flexural vibration and buckling of isotropic and orthotropic rectangular plates". Journal of Sound and Vibration 108(1), 51-62.

Dugdale D.S. 1984. Vibration modes of a disc of wood laminate. International Journal of Engineering Science (22). p77-86.

Hughes O.F. 1988. Ship Structural Design. Jersey city, New Jersey: Society of Naval Architects and Marine Engineers.

Winandy, J.E. 1994. Wood Properties. Encyclopedia of Agricultural Science, Vol. 4, Orlando, FL: Academic Press. p549-561.

Lekatompessy, D.R. 2005. Tinjauan pengaruh getaran mesin terpasang terhadap kekuatan konstruksi pondasi kapal tradisional. Jurnal Teknologi Fakultas Teknik. p27-35.

Lekatompessy, D.R. 2008. Karet sebagai peredam getaran efektif motor kapal-kapal ikan tradisional 10-30GT (Tipe Outboard Engine) ditinjau dari segi keselamatan dan kesehatan kerja. [Tidak Dipublikasikan] Ambon: Universitas Pattimura.

Lekatompessy, D.R. 2009. Pengaruh pengancingan pondasi mesin terhadap kekuatan struktur kapal kayu tradisional. [Tidak Dipublikasikan] Ambon: Universitas Pattimura.

Lekatompessy D.R., Sulaiman O.O, Ferry M., De Lima E.J. dan Manuputty M. 2013. Rubber as an effective vibration absorber of outboard engine at small traditional fishing boats from the human health and safety point of view. Journal of Engineering, Computers \& Applied Sciences (2). p7-12.

Nakao T., Tanaka, C dan Takahashi, A. 1987. Experimental Study of Flexural Vibration Of Orthotropic, Viscoelastic plates. Journal of Sound and Vibration (116). p465-473.

Craik, R.J.M dan Galbrun, L. 2005. Vibration transmission through a frame typical of timber-framed buildings. Journal of Sound and Vibration (281). p763-782. 
Soegihardjo, O. dan Suhardjono 2014. Simulasi untuk memprediksi pengaruh stiffener terhadap peningkatan kekakuan benda kerja. Jurnal Teknik Mesin UK Petra (14). p40-46.

Tan M.H.M.A., Lile, N.L.T., Mat, $F$ dan Yaacob, S. 2011. Characterization of materials by vibration technique. IIUM Engineering Journal, (Special Issue, Mechanical Engineering). p77-84.

Lin T.R., Pan, J., O'Shea, P.J. dan Mechefske, C.K. 2009. A study of vibration and vibration control of ship. Journal Marine Structures (22). p730-743.
Van Gunsteren, F.F. 1974. Some further calculations of wave-induced ship hull vibrations. Dalam: Bishop RED, Price WG, editors Proceedings of Dynamics of Marine Vehicles and Structures in Waves. New York: Mechanical Engineering Publications. p278-290.

Xia L.J., Wu W.G., Weng C.J. dan Jin X.D. 2000. Analysis of fluid-structure coupled vertical vibration for high speed ships. Journal of Ship Mechanics (4). p43-50.

Yucel, A. dan Arpaci, A. 2013. Free and forced vibration analyses of ship structures using the finite element method. Journal of Marine Science Technology (18). p324338. 